\title{
Prospecção Tecnológica de Aplicativos de Colaboração de Usuários para Avaliação e Medição de Resultados de Serviços
}

\section{Technological Prospection of User Collaboration Applications for Service Evaluation and Measurement}

\author{
Adison Mascarenhas ${ }^{1}$ \\ Witalo Tedesco Paim ${ }^{1}$ \\ Emillyn Bárbara de Assunção Pantoja ${ }^{1}$ \\ Leandro de Oliveira Ferreira ${ }^{1}$ \\ Elias Fagury Neto ${ }^{1}$ \\ ${ }^{1}$ Universidade Federal do Sul e Sudeste do Pará, Marabá, PA, Brasil
}

\begin{abstract}
Resumo
O controle social das ações do estado se fortalece dentro da legislação pátria, possibilitando que usuários, por meio de tecnologias colaborativas, forneçam informações para avaliação e medição de serviços públicos, fortalecendo a atuação das instituições. Este trabalho teve como objetivo abordar a prospecção tecnológica de aplicativos de colaboração de usuários, com vistas à criação de banco de dados, para avaliação e medição de resultados de serviços. Foram identificados em bases de dados, nacionais e internacionais, artigos sobre a temática, a fim de verificar a maturidade tecnológica e outros aspectos relacionados à utilização de aplicativos na avaliação e medição de resultados de serviços. Dos resultados obtidos, constatou-se a existência de estudos distintos; no entanto, a pesquisa identificou proposições pertinentes à temática proposta. Ao analisar os aspectos da prospecção, concluiu-se que o desenvolvimento de aplicativos atende a uma demanda que a cada dia se alinha aos recursos tecnológicos disponíveis no mercado.
\end{abstract}

Palavras-chave: Aplicativos. Avaliação. Prospecção.

\begin{abstract}
The social control of state actions is strengthened within the national legislation, enabling users, through collaborative technologies, to provide information for evaluation and measurement of public services, strengthening the performance of institutions. This work aimed to address the technological prospection of user collaboration applications, with a view to database creation, for evaluation and measurement of service results. Articles on the theme were identified in national and international databases, in order to verify technological maturity and other aspects related to the use of applications in the evaluation and measurement of service results. From the obtained results, it was verified the existence of distinct studies; However, the research identified propositions pertinent to the proposed theme. By analyzing the aspects of prospecting, it was concluded that application development meets a demand that daily aligns with the technological resources available in the market.
\end{abstract}

Keywords: Applications. Evaluation. Prospection.

Área Tecnológica: Propriedade Intelectual. Prospecção Tecnológica. 


\section{Introdução}

A disponibilização de soluções de Tecnologias da Informação e Comunicação (TIC) que possibilitem melhor atendimento aos usuários é crescente e, habitualmente, são respostas às grandes demandas que se verificam em cada tempo, no presente caso, a resolução de problemas relacionados à infraestrutura, segurança, acesso, sinalização, serviços, entre outros, nas instituições públicas. A questão é tratada como tópico relevante e central na Administração Pública, dado que os investimentos em TIC criam condições para o surgimento das sociedades do conhecimento, se tornando um instrumento capaz de permitir a interação entre sociedade, empresas e governos (FILHO; GOMES, 2004; BRAGA et al., 2014).

Considerando que a participação social e o controle das ações do estado, no que diz respeito à execução e gestão de políticas públicas, têm muitas limitações, uma solução de tecnologia de informação que registre as ocorrências e estabeleça um canal de comunicação com o público usuário, poderá possibilitar maior qualidade na execução de serviços públicos. Segundo a Controladoria Geral da União (CGU, 2019), "[...] cada cidadão possui fundamental importância na tarefa de participar de gestão e de exercer o controle social do gasto público".

Trata-se de inovações tecnológicas em serviços ou processos, que podem ser promovidas pelos próprios servidores públicos para a melhoraria do desempenho dos serviços prestados à sociedade, de forma incremental, sem a necessidade de mudanças radicais e sistêmicas (KLUMB; HOLFFMANN, 2016).

A Constituição Federal de 1988 (CF/88) direcionou normativas relacionadas à atividade estatal, entre elas, o artigo 37, o qual disciplina que "[...] a administração pública direta e indireta de qualquer dos Poderes da União, dos Estados, do Distrito Federal e dos Municípios obedecerá aos princípios de legalidade, impessoalidade, moralidade, publicidade e eficiência" (BRASIL, 1988, art. 37).

O parágrafo $3^{\circ}$ e o inciso I, do citado artigo, expressam que a lei disciplinará as formas de participação do usuário na administração pública direta e indireta, regulando especialmente, às reclamações relativas à prestação dos serviços públicos em geral, asseguradas a manutenção de serviços de atendimento ao usuário e a avaliação periódica, externa e interna, da qualidade dos serviços.

Por meio da Lei Federal n. 13.460, de 26 de junho de 2017, que dispõe sobre participação, proteção e defesa dos direitos do usuário dos serviços públicos da administração pública, o parágrafo $3^{\circ}$, inciso I, entre outros dispositivos constitucionais, foi regulamentado (BRASIL, 2017b).

Popularmente, a Lei n. 13.460/2017 ficou conhecida como código de defesa do usuário do serviço público; para o professor Emerson Gabardo (2017), "[...] trata-se de uma importante regulação, mas que demorou quase trinta anos para ser editada". Segundo o citado professor, "[...] não que inexistissem normas assemelhadas, mas a Constituição de 1988 e a Reforma do Estado de 1998 exigiam mais em termos de controle do Estado na gestão e execução dos serviços públicos prestados" (GABARDO, 2017).

Logo, torna-se necessário o desenvolvimento de mecanismos que possibilitem o controle e gestão dos serviços, aqui destacados os serviços prestados de forma indireta pala Administração Pública, quais sejam, os serviços terceirizados que são prestados por empresas contratadas por meio das diversas modalidades de licitação pública. 
Nesse sentido, a Instrução Normativa n. 5, de 26 de maio de 2017 (IN n. 05/2017), da Secretaria de Gestão do Ministério do Planejamento, Desenvolvimento e Gestão, dispõe sobre as regras e diretrizes do procedimento de contratação de serviços sob o regime de execução indireta no âmbito da Administração Pública Federal direta, autárquica e fundacional, estabelecendo atividades de gestão e fiscalização da execução dos contratos administrativos (BRASIL, 2017a).

Assim, o artigo 39 da citada instrução assegura que as atividades de gestão e fiscalização da execução contratual são o conjunto de ações que têm por objetivo aferir o cumprimento dos resultados previstos pela Administração para os serviços contratados. $\mathrm{O}$ artigo 40 define que o conjunto de atividades de que trata o artigo anterior compete ao gestor da execução dos contratos, auxiliado pela fiscalização técnica, administrativa, setorial e pelo público usuário, conforme o caso (BRASIL, 2017a).

O inciso V, do artigo 40 da IN n. 05/2017, conceitua a fiscalização pelo público usuário, discorrendo ser

[...] o acompanhamento da execução contratual por pesquisa de satisfação junto ao usuário, com o objetivo de aferir os resultados da prestação dos serviços, os recursos materiais e os procedimentos utilizados pela contratada, quando for o caso, ou outro fator determinante para a avaliação dos aspectos qualitativos do objeto. (BRASIL, 2017a, art. 40)

Até onde foi pesquisado, não há registros anteriores de aplicativos para acompanhamento da execução contratual por pesquisa de satisfação junto ao usuário, algo que pode estar relacionado às recentes atualizações legislativas, bem como a cultura de não proteção de softwares pela comunidade que os desenvolve. Nesse sentido, registra-se que a proteção de softwares constitui importante indicador tecnológico e revela a excelência tecnológica do público desenvolvedor, atribuindo segurança jurídica e benefícios econômicos da exploração dessas criações intelectuais (LIMA; LIMA; GUIMARÃES, 2019).

Dessa forma, o presente trabalho teve como objetivo abordar a prospecção tecnológica de aplicativos de colaboração de usuários para avaliação e medição de resultados de serviços. Foram identificados, em bases de dados nacionais, artigos e proteções de aplicativos sobre a temática, para verificar a maturidade tecnológica e outros aspectos relacionados à utilização de aplicativos na avaliação e medição de resultados de serviços.

\section{Metodologia}

A prospecção foi realizada nos meses de dezembro de 2018 e janeiro de 2019 com base nos artigos publicados no período de 2001 a 2018, e depósito do pedido de registro de aplicativos realizados no intervalo de 1994 a 2018. A base de dados de artigos foi a Revista do Serviço Público ${ }^{1}$, através do Portal de Periódicos Capes, a de depósito de pedido de registro de aplicativos, foi o Instituto Nacional da Propriedade Industrial (INPI) ${ }^{2}$.

Foi realizado, ainda, uma pesquisa exploratória, sendo bibliográfica em relação meios de busca do assunto pertinente ao tema em estudo. À medida que se dispõe de um sistema de 
classificação, torna-se possível reconhecer as semelhanças e diferenças entre as diversas modalidades de pesquisa (GIL, 2010).

No levantamento bibliográfico realizou-se a busca por catálogos, estes são publicados pelas editoras, ou pertencem a bibliotecas públicas. Buscou-se, ainda, catálogos específicos de periódicos, visualizando o rol de artigos publicados. Em um segundo momento, tendo em mãos o livro ou periódico, levantou-se o tema dos assuntos abordados, e ainda, o resumo, este último por oferecer elementos de identificação do trabalho de forma analítica. Por último, foi realizada a verificação da bibliografia ao final do livro e do artigo, constituído, em geral, pela indexação de artigos de livros, teses, folhetos, periódicos, relatórios, comunicações e outros documentos sobre o mesmo tema (LAKATOS, 2017).

Para Ribeiro (2018), a busca de publicações científicas consiste na segunda etapa de uma busca de anterioridade e determina se o conhecimento já está em domínio público por meio da publicação de artigos ou de defesas de trabalhos de conclusão de projetos ou cursos, por exemplo, de bolsistas de iniciação científica ou tecnológica, graduandos, mestrandos, doutorandos ou alunos de especialização. Segundo a citada autora, a busca concentra-se em homepages de eventos ou em base de dados de periódicos científicos, como Scielo, Scopos, Science Direct, Pub Med, Google Acadêmico e Web of Science, portal de periódicos da CAPES e editoras mais conhecidas, como Elsevier, Thompson Reuters e Taylor Francis, entre outros (RIBEIRO, 2018, p. 115).

Entre os critérios de busca estabelecidos, foi realizado a identificação de trabalhos que apresentassem a seguinte temática: controle social, participação popular, registro de ocorrências e avaliação de serviços públicos. Nesse sentido, foram localizados 37 registros de softwares e oito artigos e/ou defesas de trabalhos de conclusão de projetos ou cursos.

\section{Resultados e Discussão}

A pesquisa teve início na plataforma on-line de pesquisa do Instituto Nacional da Propriedade Industrial (INPI), no campo de pesquisa "título". No Quadro 1, constam as palavras-chave pesquisadas e o número total de registros de softwares analisados.

Quadro 1 - Resultado da pesquisa

\begin{tabular}{|c|c|}
\hline PALAVRAS-CHAVE & BASE DE DADOS \\
\hline Usuário & INPI \\
\hline Serviços Públicos & 22 \\
\hline Públicos & 1 \\
\hline Aplicativo de Ocorrências & 13 \\
\hline TOTAL DE REGISTROS DE SOFTWARES ANALISADOS & 1 \\
\hline
\end{tabular}

Fonte: Elaborado pelos autores deste artigo a partir de dados do INPI (2019)

$\mathrm{Na}$ prospecção foi observada a existência de vários aplicativos, a maioria relacionados a operações de atendimento ao usuário e registro de ocorrência que, de certa maneira, são 
pertinentes ao tema do presente estudo, no entanto, a pesquisa restou ausente a existência de aplicativos de colaboração de usuários para avaliação e medição de resultados de serviços. Este cenário ratifica o entendimento de que atualmente a Administração Pública Federal não dispõe de ferramenta tecnológica para mensuração e avaliação de serviços, sendo uma demanda crescente que, alinhada aos recursos tecnológicos disponíveis atualmente no mercado de softwares, possibilita respostas às inquietações que se verificam em cada tempo, legitimando a atuação das instituições, por meio da avaliação do público usuário.

Em pesquisa realizada por Nishiyama et al. (2017, p. 10) visualiza-se a pressão da sociedade e da mídia pela prestação de serviços mais eficientes. Corroborando com esse entendimento, a pesquisa afirma que a administração, por meio de seus gestores, precisa direcionar esforços buscando instrumentalizar uma gestão mais atualizada, transparente e cientificamente reconhecida como eficiente na busca da valorização dos recursos do Estado, na satisfação do cidadão-cliente, e na valorização dos funcionários públicos e ambiente moral do Estado.

No Gráfico 1, é apresentado o quantitativo total de registros realizados junto ao INPI, e a evolução no tempo referente aos registros de softwares analisados de 1994 a 2018.

Gráfico 1 - Evolução de tecnologias no tempo nas bases de dados do INPI (2019)

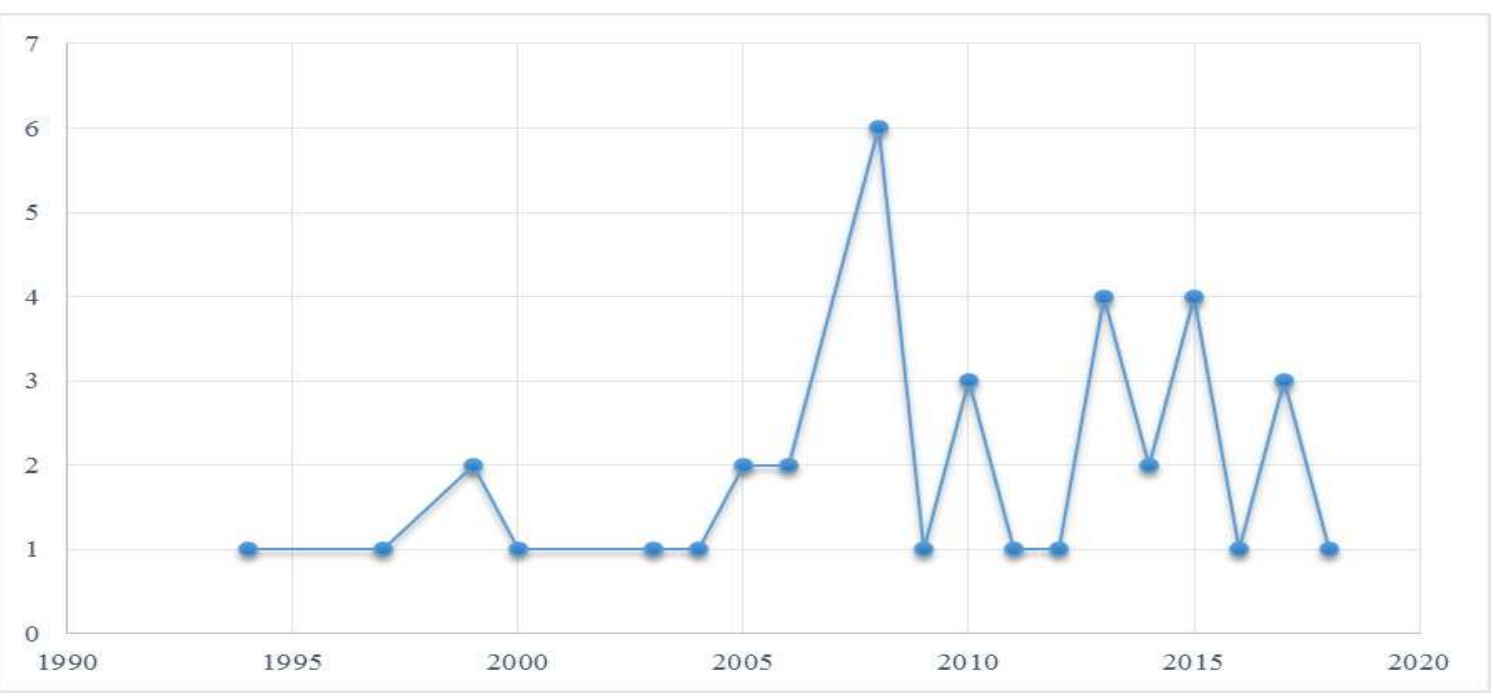

Fonte: Elaborado pelos autores deste artigo a partir de dados do INPI (2019)

Os números apresentados no Gráfico 1 representam o total de 38 registros de softwares, o parâmetro para busca destes registros são as palavras-chave indicadas na Tabela 1. Desse total, foram contabilizados 37 registros. $\mathrm{O}$ motivo da contabilização a menor foi a duplicidade de um mesmo registro em 2005 a partir do tratamento dos dados por meio da utilização das palavras-chave "Serviços Públicos" e "Públicos".

Assim, analisando a evolução no tempo dos registros realizados no intervalo de 1994 a 2018, em uma ordem crescente, dentro dos parâmetros estabelecidos na Tabela 1, pode-se observar um aumento no número de registros a partir de 2005, embora esse aumento seja irregular ao longo do tempo.

No que tange às solicitações de registros de softwares, percebe-se maior interesse de registros concentrados a pessoas jurídicas, conforme Gráfico 2, com grande destaque a centros espe- 
cializados em pesquisas, pessoa jurídica de direito privado, cuja a titularidade está especificada no Gráfico 3.

Gráfico 2 - Evolução dos depósitos por depositante nas bases de dados do INPI (2019)

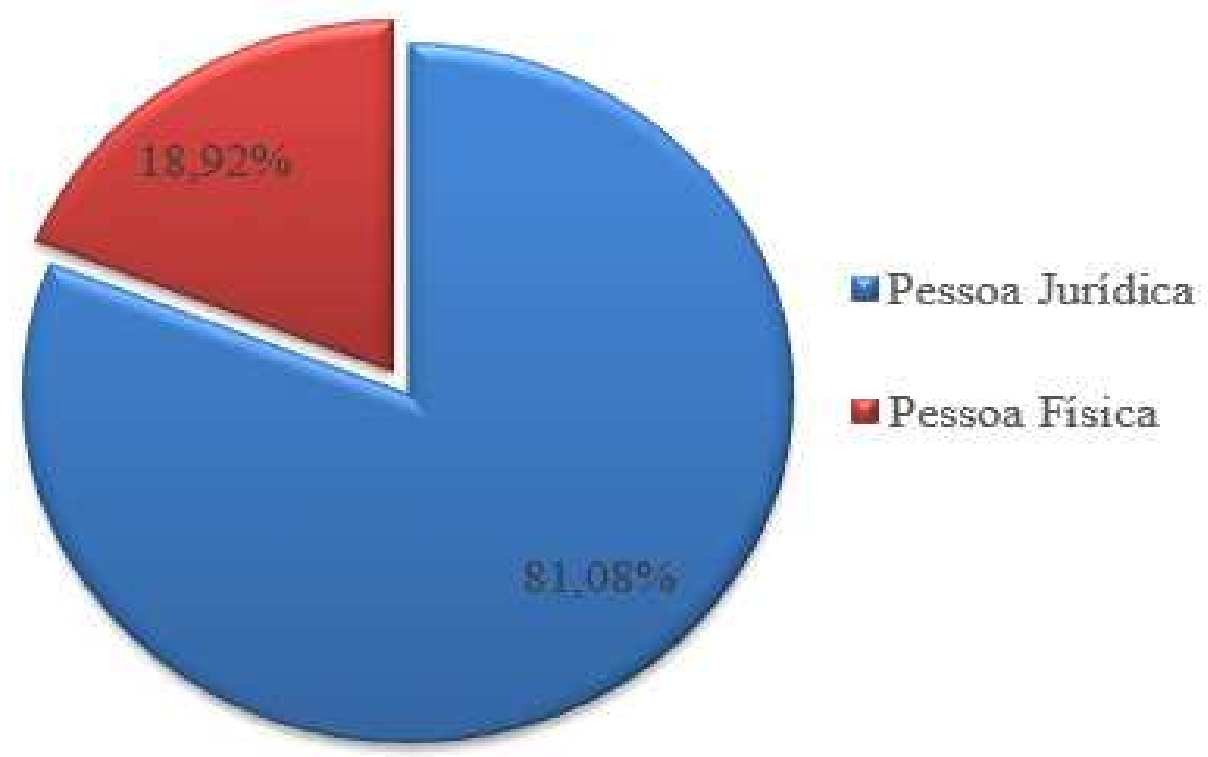

Fonte: Elaborado pelos autores deste artigo a partir de dados do INPI (2019)

Do maior percentual das solicitações de registros de softwares parametrizados na Tabela 1, $28,75 \%$ são de institutos de pesquisas, $10,53 \%$ de empresas públicas, universidades públicas representam 10,53\%, demais órgãos públicos 5,26\%, universidades privadas $2,63 \%$ e demais pessoas jurídicas de direito privado, 23,38\%.

Nos Gráficos 3 e 4 serão mostrados os dados levantados a respeito da evolução dos depósitos por titular, no período de 1994 a 2018, e a evolução dos principais inventores.

Gráfico 3 - Evolução dos depósitos por titular nas bases de dados do INPI (2019)

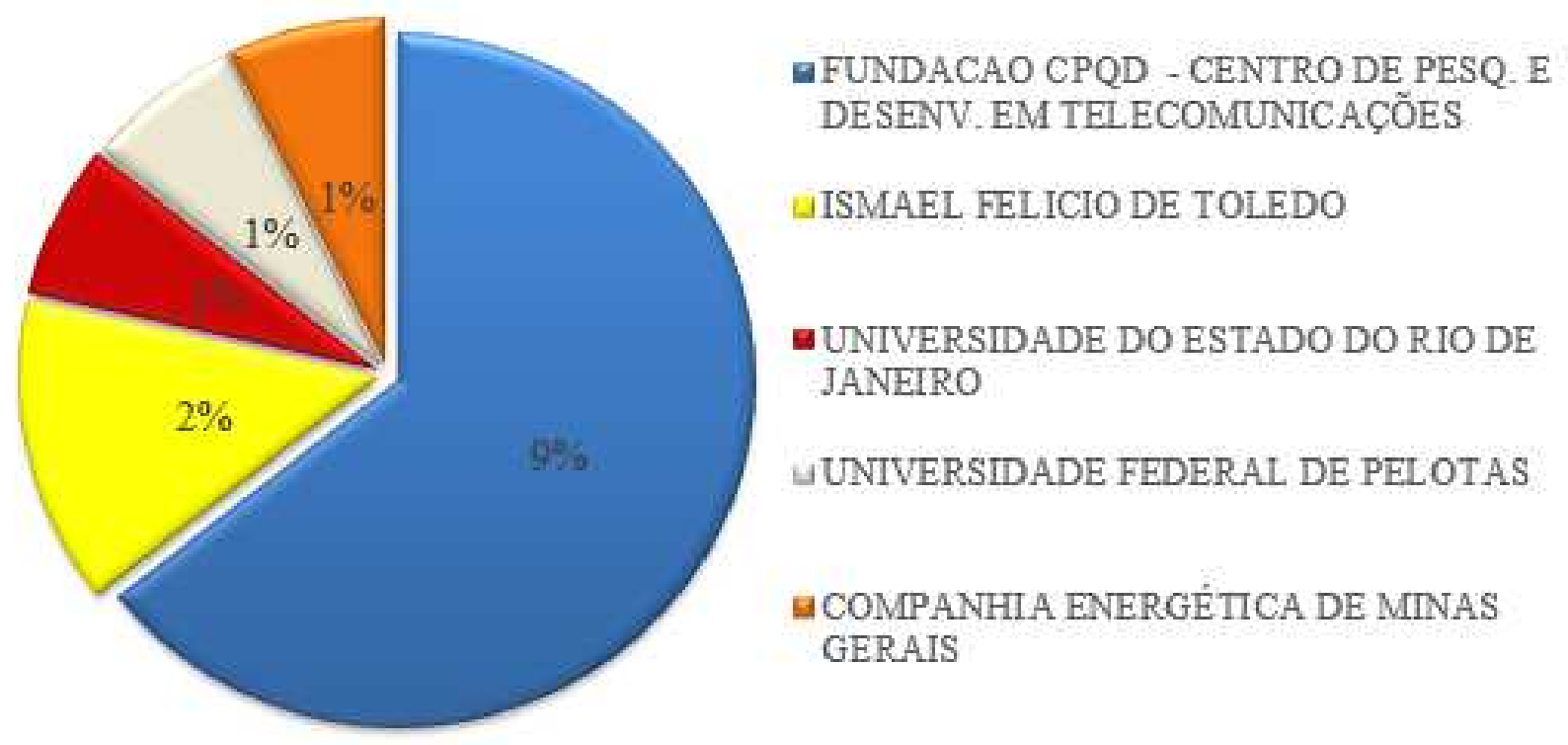

Fonte: Elaborado pelos autores deste artigo a partir de dados do INPI (2019) 
O Gráfico 3 representa o quantitativo de registro por titularidade, com destaque para o Centro de Pesquisa e Desenvolvimento em Telecomunicações (CPQD), que apresentou nove registros. Para melhor visualização, foi colocado em destaque o grupo dos primeiros cinco registros, e, diferente da titularidade de "Ismael Felicio de Toledo", convém mencionar que os demais só apresentaram um registro.

Gráfico 4 - Evolução dos depósitos por titular nas bases de dados do INPI (2019)

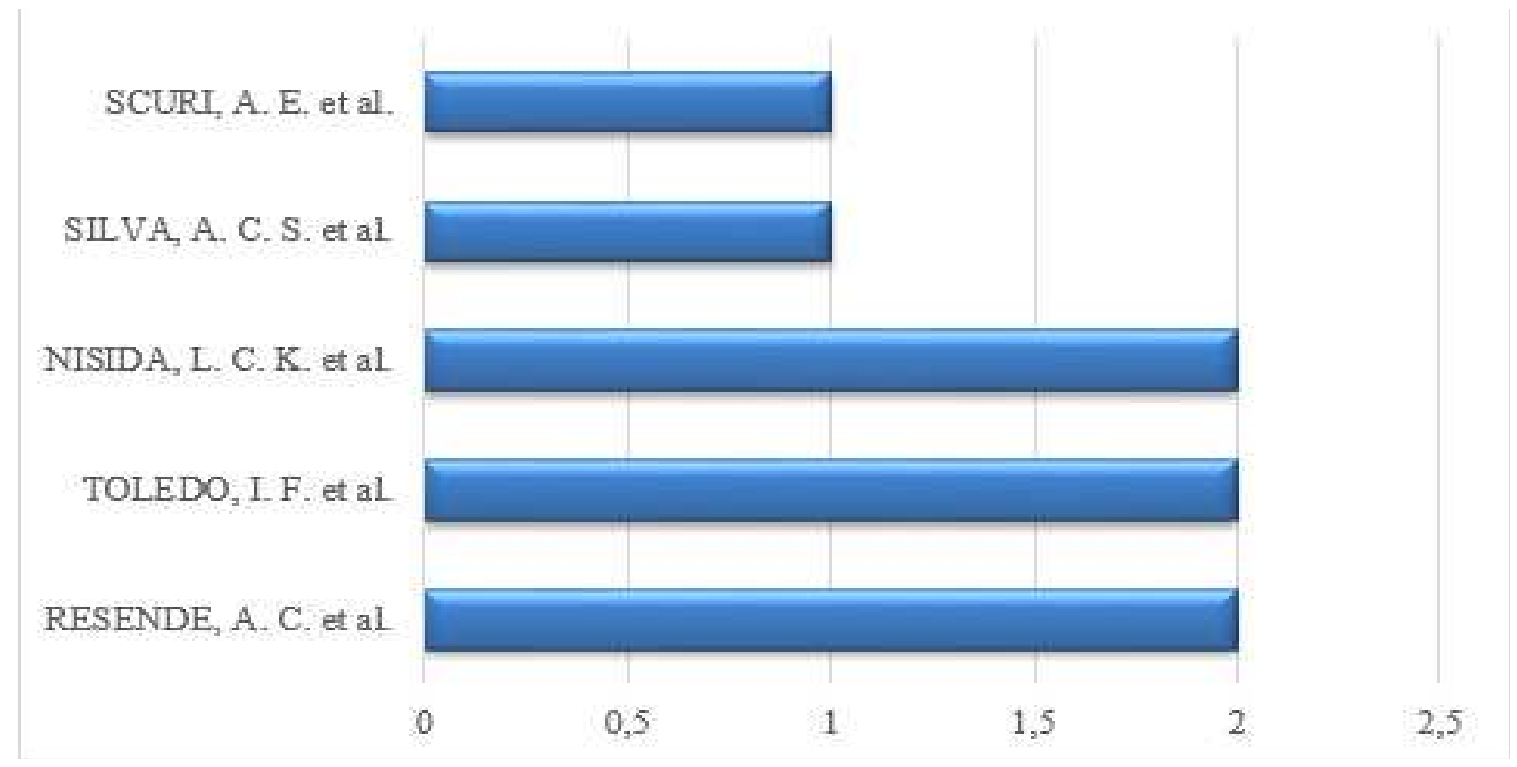

Fonte: Elaborado pelos autores deste artigo a partir de dados do INPI (2019)

O Gráfico 4 apresenta os principais inventores. Foi verificado que a maioria dos registros estão apropriados ou licenciados em nome dos titulares identificados no Gráfico 3.

Por fim, o Gráfico 5 apresenta as principais linguagens de programação utilizada no desenvolvimento dos aplicativos.

Por meio das informações prospectadas torna-se possível delimitar as linguagens de programação próximas às tendências e recursos disponíveis no mercado, eliminando discrepância em um eventual cenário de desenvolvimento de aplicativos. 
Gráfico 5 - Principais linguagens de programação

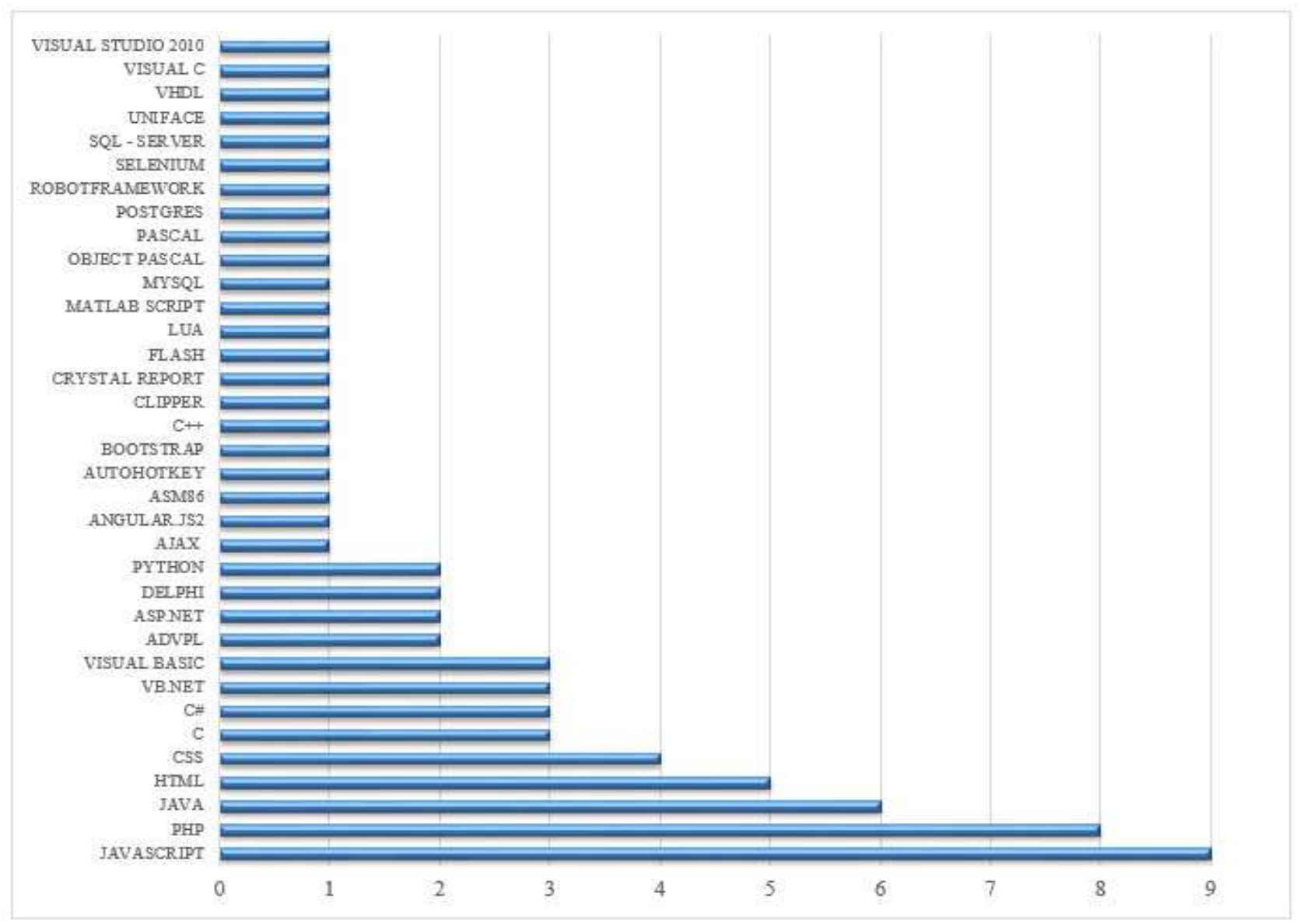

Fonte: Elaborado pelos autores deste artigo a partir de dados do INPI (2019)

No Quadro 2, são mostradas publicações as de artigos ou defesas de trabalhos de conclusão de projetos ou cursos relacionados ao tema, que serviram de motivação para o desenvolvimento do presente estudo.

Quadro 2 - Resumo dos artigos pesquisados

REFERÊNCIAS

[ENAP, 2018a]

[ENAP, 2018]

[MARINHO et al, 2018]

[EVANGELISTA et al., 2016]

[LIMA; VIEIRA, 2011]

[MIRANDA et al., 2010]

[NETO et al., 2018]

[SOUZA et al., 2016]

\section{TEMA ABORDADO}

Pesquisa sobre serviços públicos de atendimento.

Gestão e fiscalização de contratos de serviços terceirizados.

Fiscalização de contratos de serviços terceirizados: desafios para a universidade pública.

Avaliação da capacidade das organizações da administração pública federal para a adoção de software como serviço público.

Desenvolvimento de sistemas como instrumento da gestão do conhecimento de Políticas Sociais.

A gestão da informação e a modelagem de processos.

Acessibilidade e Tecnologia.

Participação cidadã na interação com o controle externo da União no Estado brasileiro do século XXI.

Fonte: Elaborado pelos autores deste artigo (2019) 
Nas produções citadas na Tabela 2 , buscou-se amadurecimento em assuntos relacionados à gestão e fiscalização de contratos administrativos, os quais são regulamentados pela Lei Federal n. 8.666, de 21 de junho de 1993, que instituiu normas para licitações e contratos da Administração Pública, entre outras providências. O monitoramento do cumprimento de obrigações contratuais assumidas pela contratada durante a execução contratual, referente à prestação de serviços, tem sido um grande desafio para a equipe de fiscalização, representada por servidores das mais diversas áreas de conhecimento.

Para Marinho (2018), os fiscais de contrato não constituem propriamente um grupo organicamente estruturado e isso dificulta a utilização do treinamento convencional. Afirma a pesquisadora que

[...] o papel do fiscal de contratos nas universidades públicas requer habilidades e conhecimentos heterogêneos, incluindo o domínio da legislação e práticas operacionais voltadas à manutenção de uma política de gestão eficiente que satisfaça o interesse público. (MARINHO, 2018, p. 444)

Nesse sentido, para identificar publicações próximas à temática, foi utilizado o Repositório Institucional da Escola Nacional de Administração Pública (ENAP), instituição que tem como finalidade promover, elaborar e executar os programas de capacitação de recursos humanos para a Administração Pública Federal, visando ao desenvolvimento e à aplicação de tecnologias de gestão que aumentem a eficácia e a qualidade permanente dos serviços prestados pelo Estado aos cidadãos, nos termos da Lei Federal n. 8.140, de 28 de dezembro de 1990.

Assim, ao analisar a pesquisa ENAP sobre o atendimento de serviços públicos, percebe-se a necessidade de verificar diferentes tipos de usuários aos quais esses serviços se destinam, e, ainda, documentação necessária para que estes tenham acesso aos serviços públicos de atendimento apresentados (ENAP, 2018a).

Os temas observados têm sido aqueles que objetivam amadurecer a cultura do planejamento e controle na administração pública, possibilitando a avaliação, pelo público usuário, aos serviços prestados pelo Estado. Ainda nesta perspectiva, a partir dos estudos levantados, considerando as recentes atualizações na legislação brasileira, constatou-se que o desenvolvimento de aplicativos atende a uma demanda que a cada dia se alinha aos recursos tecnológicos disponíveis no mercado.

\section{Considerações Finais}

Diante de todo o exposto, por meio da base de dados do INPI, a pesquisa identificou a existência de vários aplicativos, a maioria relacionados a operações de atendimento ao usuário e registro de ocorrência que, de certa maneira, são pertinentes ao tema do presente estudo.

Na prospecção de artigos, verificou-se que o amadurecimento em assuntos relacionados a gestão e fiscalização de contratos administrativos, alinhados às recentes atualizações da legislação, é necessário para o desenvolvimento de tecnologias colaborativas em harmonia com a legislação aplicável à matéria. 
Assim, o desenvolvimento de aplicativos atende a uma demanda que se alinha aos recursos tecnológicos disponíveis no mercado, possibilitando à administração pública maior disponibilidade de serviços.

\section{Referências}

BRAGA, L. V. et al. O papel do Governo Eletrônico no fortalecimento da governança do setor público. Revista do Serviço Público, [S.l.], v. 59, n. 1, p. 5-21, 18 fev. 2014. Disponível em: https://revista.enap.gov.br/index.php/RSP/article/view/137. Acesso em: 16 dez. 2019.

BRASIL. Constituição (1988). Constituição da República Federativa do Brasil de 1988. Promulgada em 5 de outubro de 1988. Brasília, DF. Disponível em: http://www.planalto.gov.br/ ccivil_03/constituicao/constituicaocompilado.htm. Acesso em: 15 dez. 2018.

BRASIL. Lei n. 8.140, de 28 de dezembro de 1990. Altera a denominação da Fundação Centro de Formação do Servidor Público - FUNCEP e dá outras providências. Diário Oficial [da] República Federativa do Brasil, Brasília, DF, 31 dez. 1990. Disponível em: http://pesquisa.in.gov.br/imprensa/ jsp/visualiza/index.jsp?data $=31 / 12 / 1990 \&$ jornal $=1 \&$ pagina $=2 \&$ totalArquivos $=168$. Acesso em: 17 jan. 2019.

BRASIL. Lei n. 8.666, de 21 de junho de 1993. Regulamenta o art. 37, inciso XXI, da Constituição Federal, institui normas para licitações e contratos da Administração Pública e dá outras providências. Diário Oficial [da] República Federativa do Brasil, Brasília, DF, 22 jun. 1993. Disponível em: http://pesquisa.in.gov.br/imprensa/jsp/visualiza/index.jsp?jornal=1\&pagina=1\&da ta $=22 / 06 / 1993$. Acesso em: 17 jan. 2019.

BRASIL. Instrução Normativa n. 5, de 26 de maio de 2017. Dispõe sobre as regras e diretrizes do procedimento de contratação de serviços sob o regime de execução indireta no âmbito da Administração Pública federal direta, autárquica e fundacional. Diário Oficial [da] República Federativa do Brasil, Brasília, DF, 26 maio 2017a. Disponível em: http://pesquisa.in.gov.br/ imprensa/jsp/visualiza/index.jsp?jornal =1\&data=26/05/2017\&pagina=90. Acesso em: 15 dez. 2018.

BRASIL. Lei n. 13.460, de 26 de junho de 2017. Dispõe sobre participação, proteção e defesa dos direitos do usuário dos serviços públicos da administração pública. Diário Oficial [da] República Federativa do Brasil, Brasília, DF, 27 jun. 2017b. Disponível em: http://pesquisa.in.gov.br/imprensa/ jsp/visualiza/index.jsp?jornal=1\&pagina=4\&data=27/06/2017. Acesso em: 15 dez. 2018.

CGU - CONTROLADORIA-GERAL DA UNIÃO. Controle Social. [2019]. Disponível em: https:// www.cgu.gov.br/assuntos/controle-social. Acesso em: 4 jul. 2019.

ENAP - ESCOLA NACIONAL DE ADMINISTRAÇÃO PÚBLICA (Brasil). Pesquisa sobre Serviços Públicos de Atendimento do Governo Federal. Cadernos ENAP, [S.l.], n 55, jun. 2018a. Disponível em: http://repositorio.enap.gov.br/handle/1/3217. Acesso em: 27 jan. 2019.

ENAP - ESCOLA NACIONAL DE ADMINISTRAÇÃO PÚBLICA (BRASIL). Manual de Gestão e de Fiscalização de Contratos de Serviços Terceirizados da Enap. Manuais e Procedimentos Técnicos, abr. 2018b. Disponível em: http://repositorio.enap.gov.br/handle/1/3130. Acesso: em 27 jan. 2019.

EVANGELISTA, Wellington Galdino; SOUZA NETO, João. Modelo de avaliação da capacidade das organizações da administração pública federal para a adoção de software as a service (SaaS) 
público. Revista do Serviço Público - RSP, [S.l.], v. 67, n. 2, p. 173-202. 2016. Disponível em: http://repositorio.enap.gov.br/handle/1/2926. Acesso em: 27 jan. 2019.

FILHO, José Rodrigues; GOMES, Natanael Pereira. Tecnologia da informação no governo federal. Revista de Administração Pública, Rio de Janeiro, v. 38, n. 1, p. 93 a 108, jan. 2004. ISSN 19823134. Disponível em: http://bibliotecadigital.fgv.br/ojs/index.php/rap/article/view/6529. Acesso em: 16 dez. 2019.

GABARDO, Emerson. O Novo Código de Defesa do Usuário do Serviço Público: Lei 13.460/17. Revista Eletrônica de Direito Administrativo Econômico, [S.I.], n. 367, 2017. Disponível em: http://www.direitodoestado.com.br/colunistas/emerson-gabardo/o-novo-codigo-de-defesa-do-usuariodo-servico-publico-lei-13-460-17. Acesso em: 15 dez. 2018.

GIL, Antônio Carlos. Como elaborar projetos de pesquisa. 5. ed. São Paulo: Atlas, 2010.

INPI - INSTITUTO NACIONAL DA PROPRIEDADE INDUSTRIAL. Portal virtual. 2019. Disponível em: http://www.inpi.gov.br/. Acesso em: 11 jan. 2019.

KLUMB, Rosangela; HOFFMANN, Micheline Gaia. Inovação no setor público e evolução dos modelos de administração pública: o caso do TRE-SC. Cadernos Gestão Pública e Cidadania, [S.l.], v. 21, n. 69, ago. 2016. ISSN 2236-5710. Disponível em: http://bibliotecadigital.fgv.br/ojs/ index.php/cgpc/article/view/53902. Acesso em: 16 dez. 2019. doi:http://dx.doi.org/10.12660/cgpc. v21n69.53902.

LAKATOS, Eva Maria. Fundamentos de metodologia científica. 8. ed. São Paulo: Atlas, 2017.

LIMA, G. M.; LIMA, T. L. M.; GUIMARÃES, P. B. V. A Proteção Jurídica de Softwares e sua Contribuição para o Desenvolvimento Brasileiro. Cadernos de Dereito Actual, Lima, n. 11, p. 161-172, 2019. Disponível em: http://cadernosdedereitoactual.es/ojs/index.php/cadernos/article/ view/392/227. Acesso em: 18 dez. 2019.

LIMA, Jonas Medeiros; VIEIRA, Fernando José Travassos. Desenvolvimento de sistemas como instrumento da gestão do conhecimento de Políticas Sociais. Especialização Enap - Trabalhos de Conclusão de Curso (TCC), 2011. Disponível em: http://repositorio.enap.gov.br/handle/1/3310. Acesso em: 27 jan. 2019.

MARINHO, Rita de Cassia Pinto et al. Fiscalização de contratos de serviços terceirizados: desafios para a universidade pública. Gest. Prod., São Carlos, v. 25, n. 3, p. 444-457, set. 2018. Disponível em: http:/www.scielo.br/scielo.php?script=sci_arttext\&pid=S0104530X2018000300444\&lng=pt\&nr m=iso. Acesso em: 31 mai. 2019. Epub 30-Jul-2018. http://dx.doi.org/10.1590/0104-530x1595-18.

MIRANDA, Silvânia Vieira de. A gestão da informação e a modelagem de processos. Revista do Serviço Público - RSP, [S.l.], v. 61, n. 1, p. 97-112, jan. 2010. Disponível em: http://repositorio. enap.gov.br/handle/1/1589. Acesso em: 27 jan. 2019.

NISHIYAMA, Mario Augusto et al. Modelo Multicritério para Avaliação de Desempenho: um estudo de caso para gestão de compras no setor público. Revista de Ciências da Administração, Florianópolis, p. 9-28, maio, 2017. ISSN 2175-8077. Disponível em: https://periodicos.ufsc.br/ index.php/adm/article/view/2175-8077.2017v19n47p9. Acesso em: 26 maio 2019. DOI: https://doi. org/10.5007/2175-8077.2017v19n47p9.

NETO, C. A. A.; ROLT, C. R.; ALPERSTEDT, G. D. Acessibilidade e Tecnologia na Construção da Cidade Inteligente. RAC, Rio de Janeiro, v. 22, n. 2, pp. 291-310, março/abril, 2018. Disponível em: http://www.scielo.br/pdf/rac/v22n2/1982-7849-rac-22-02-0291.pdf. Acesso em: 27 jan. 2019. 
RIBEIRO, Núbia Moura. Prospecção tecnológica [Recurso eletrônico on-line]. Salvador (BA): IFBA, 2018. Disponível em: http:/www.profnit.org.br/wp-content/uploads/2018/08/PROFNIT-SerieProspeccao-Tecnologica-Volume-1-1.pdf. Acesso em: 29 jan. 2019.

SOUZA, Tiago Marafante Lins de. Participação cidadã na interação com o controle externo da União no Estado brasileiro do século XXI. Especialização Enap - Trabalhos de Conclusão de Curso (TCC), jul. 2016. Disponível em: http://repositorio.enap.gov.br/handle/1/2472. Acesso em: 27 jan. 2019.

\section{Sobre os Autores}

\section{Adison Mascarenhas}

E-mail: adisom@hotmail.com

Mestrando em Propriedade Intelectual e Transferência de Tecnologia para a Inovação (PROFNIT) pela Universidade Federal do Sul e Sudeste do Pará (UNIFESSPA); especialista em Administração e Finanças pela Escola Superior Aberta do Brasil (ESAB); especialista em Direito Constitucional pela Faculdade Futura (FUTURA); especialista em Docência para a Educação Profissional, Científica e Tecnológica pelo Instituto Federal do Pará (IFPA); e graduado em Sistemas de Informação pela Faculdade Metropolitana de Marabá (CEMAR).

Endereço profissional: Folha 17, Quadra 04, Lote Especial, s/n, Nova Marabá, Marabá, PA. CEP: 68505-080.

\section{Witalo Tedesco Paim}

E-mail:witalotedesco@gmail.com

Mestrando em Propriedade Intelectual e Transferência de Tecnologia para a Inovação (PROFNIT) pela Universidade Federal do Sul e Sudeste do Pará (UNIFESSPA); especialista em Gestão Estratégica de Negócios pela Universidade Norte do Paraná (UNOPAR); especialista em Marketing pela Universidade da Amazônia (UNAMA); e graduado em Administração pela Universidade da Amazônia (UNAMA).

Endereço profissional: Folha 17, Quadra 04, Lote Especial, s/n, Nova Marabá, Marabá, PA. CEP: 68505-080.

\section{Emillyn Bárbara de Assunção Pantoja}

E-mail: emillynbarbara@hotmail.com

Mestranda em Propriedade Intelectual e Transferência de Tecnologia para a Inovação (PROFNIT) pela Universidade Federal do Sul e Sudeste do Pará (UNIFESSPA); especialista em Direito Tributário pela Faculdade Venda Nova Imigrante (FAVENI); e graduada em Direito pela Universidade Federal do Pará (UFPA).

Endereço profissional: Folha 17, Quadra 04, Lote Especial, s/n, Nova Marabá, Marabá, PA. CEP: 68505-080.

\section{Leandro de Oliveira Ferreira}

E-mail: leandro.ferreira@unifesspa.edu.br

Doutor em Administração pela Universidade Metodista de Piracicaba (UNIMEP); Mestre em Administração pela Universidade Paulista (UNIP); e graduado em Administração de Empresas pelo Centro Universitário da Fundação Educacional de Barretos (UNIFEB).

Endereço profissional: Rua Rio Grande do Sul, 260, Centro, Rondon do Pará, PA. CEP: 68.638-000.

\section{Elias Fagury Neto}

E-mail: fagury@unifesspa.edu.br

Doutor e mestre em Engenharia pela Universidade Federal de São Carlos (UFSCar); e graduado em Engenharia Química pela Universidade Federal do Pará (UFPA).

Endereço profissional: Folha 17, Quadra 04, Lote Especial, s/n, Nova Marabá, Marabá, PA. CEP: 68505-080. 